\title{
In memoriam: Professor Malcolm Molyneux (1943- 2021)
}

\author{
Adamson S. Muula,
}

Editor-in-Chief, Malawi Medical Journal and Head of Public Health, The Kamuzu University of Health Sciences (KUHeS), Blantyre, Malawi

We, at the Malawi Medical Journal (www.medcol.mmj. mw) were saddened by the demise of Professor Malcolm Molyneux, former Editor-in-Chief (EIC) of our journal on 17th November 2021. Malcolm passed away in the UK where he had been since 2015 after almost three decades of service to Malawi and our journal. The Malawi Medical Journal started off as the Medical Quarterly for which Prof Molyneux was its EIC from 1980 to 1984. After some break at the Journal, Malcolm returned to head the journal again before handing over to Dr Chiwoza Bandawe, who himself was succeeded by Dr Lucinda Manda-Taylor before I took over in 2019. We share history with the Tropical Doctor journal, as Prof Molyneux also served as its IEC for some period.

Professor Molyneux's contribution to medical education, practice and research have been well chronicled in Malawi and elsewhere. Having started his Malawi clinical work with St Luke's Anglican Mission Hospital at Malosa, Malcolm moved on to the Queen Elizabeth Central Hospital (QECH), currently the largest tertiary level hospital in Malawi. He and his colleagues Terrie Taylor and Jack Wirima established malaria research which culminated in the creation of the Blantyre Coma Score and enhanced understanding

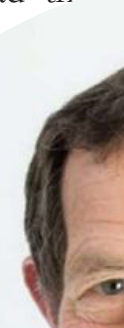
It is impossible to chronicle Malcolm's achievements without the risk of under-reporting. It is important however to observe that Prof Molyneux established the MalawiLiverpool-Wellcome Trust Clinical Laboratories Programme (MLW), a premier research institute affiliated with the Malawi College of Medicine (the latter is now the Kamuzu University of Health Sciences, after being combined with the Kamuzu College of Nursing as from 4th May 2021).

In 1985, working with others including Drs Hetherwick Ntaba and Peter Chimimba as well as experts from Britain and West Germany, the Tripartite Report (because it involved three countries i.e. Britain, West Germany and Malawi) which recommended the establishment of a medical school in Malawi was submitted to then Head of State (Dr Hastings Kamuzu Banda), himself a medical doctor.

Our thoughts and prayers at the Journal are with his wife, Prof Elizabeth Molyneux (nee, Neech) who taught and examined me in Paediatrics and Child Health for my medical degrees. She, herself, is an accomplished medical educator and practitioner. on malaria globally. The BCS is still used to estimate consciousness level among children with malaria and other conscious-altering clinical conditions in low-income countries. Prof Molyneux served on committees of the Malaria Control Programme in Malawi, the World Health Organization, and GSK's candidate malaria vaccine RTS,S. He also served as the Ombudsman for The Lancet. 